\title{
Matrix metalloproteinase-1 expression in breast carcinoma: a marker for unfavorable prognosis
}

\author{
Ji Wang ${ }^{1,2, *}$, Chenyang $\mathrm{Ye}^{3, *}$, Demin $\mathrm{Lu}^{3,4, *}$, Yongxia Chen ${ }^{1,2}$, Yunlu Jia ${ }^{1,2}$, Xiaogang \\ Ying ${ }^{1,2}$, Hanchu Xiong ${ }^{1,2}$, Wenhe Zhao ${ }^{1,2}$, Jichun Zhou ${ }^{1,2}$ and Linbo Wang ${ }^{1,2}$ \\ ${ }^{1}$ Department of Surgical Oncology, Sir Run Run Shaw Hospital, College of Medicine, Zhejiang University, Hangzhou, Zhejiang, \\ 310016, China \\ ${ }^{2}$ Biomedical Research Center and Key Laboratory of Biotherapy of Zhejiang Province, Hangzhou, Zhejiang, 310016, China \\ ${ }^{3}$ Cancer Institute, Key Laboratory of Cancer Prevention and Intervention, China National Ministry of Education, Second \\ Affiliated Hospital, School of Medicine, Zhejiang University, Hangzhou, Zhejiang, 310009, China \\ ${ }^{4}$ Department of Medical Oncology, Second Affiliated Hospital, School of Medicine, Zhejiang University, Hangzhou, Zhejiang, \\ 310009, China \\ "These authors have contributed equally to this work \\ Correspondence to: Wenhe Zhao, email: zhaowh@srrh.com
}

Jichun Zhou, email: jichun-zhou@zju.edu.cn

Linbo Wang, email: 3198012@zju.edu.cn

Keywords: MMP1, breast cancer, immunohistochemistry, prognosis, overall survival

Received: June 27, $2017 \quad$ Accepted: August 04, $2017 \quad$ Published: August 24, 2017

Copyright: Wang et al. This is an open-access article distributed under the terms of the Creative Commons Attribution License 3.0 (CC BY 3.0), which permits unrestricted use, distribution, and reproduction in any medium, provided the original author and source are credited.

\section{ABSTRACT}

Matrix metalloproteinase-1 (MMP1) is a member of the matrix metalloproteinases family, and its aberrant expression is implicated in tumor invasion and metastasis. However, the relationship between MMP1 abnormal expression and clinical outcome in breast cancer patients remains to be elucidated. To address this issue, we conducted immunohistochemistry in breast cancer and adjacent normal tissues, and mined the transcriptional and survival data of MMP1 in breast cancer patients through Oncomine, Kaplan-Meier Plotter, bc-GenExMiner, COSMIC and cBioPortal databases. First, we found that both protein and MRNA levels of MMP1 expression were significantly higher in breast cancer tissues. Second, high MMP1 mRNA expression correlated with worse overall survival among grade II $(H R=1.75 ; p=0.011)$, nodal-negative $(H R=2.00 ; p$ $=0.00028)$, ER-positive $(H R=1.61 ; p=0.00027)$ and HER2-negative $(H R=3.17 ; p=$ 0.029 ) patients with breast cancer by using Kaplan-Meier plotter database. Third, the overexpression of MMP1 was associated with unfavorable survival results including overall survival $(H R=1.6 ; p=1.6 e-05)$, relapse free survival $(H R=1.78 ; p<1 e-16)$ and distant metastasis free survival $(H R=1.65 ; p=5.3 e-05)$ in patients with breast cancer. Taken together, the expression status of MMP1 is a significant prognostic indicator and a potential drug target for breast cancer.

\section{INTRODUCTION}

Breast cancer $(\mathrm{BC})$ is one of the most common cancers and one of the major cause of cancer-related deaths worldwide [1]. BC is known to be a heterogeneous disease of distinct histological and biological subtypes with different pathological, molecular and clinical features. Although current prognostic and predictive biomarkers have markedly improved treatment options for patients with $\mathrm{BC}$, intratumor heterogeneity in $\mathrm{BC}$ still complicates the diagnosis and treatment, and influences the clinical outcome. Therefore, more reliable markers are still required to further improve therapeutic strategy for individual patients. 
Matrix metalloproteinases (MMPs), a family of enzymes that degrade numerous kinds of extracellular matrix (ECM), were reported to play a key role in the metastatic process of cancer cells [2, 3]. Among all the identified MMPs, matrix metalloproteinase-1 (MMP1), also termed as interstitial collagenase or fibroblast collagenase, is the most ubiquitously expressed interstitial collagenase and specifically breaks down the interstitial collagens I, II, and III. A plenty of studies indicated that MMP1 is implicated in the progression and metastasis of tumor cells [4].

High expression of MMP1 has been identified in various kinds of cancers, and its overexpression has been proved to be correlated with unfavorable clinical outcome in malignancies such as hepatocellular carcinoma [5], gallbladder carcinoma [6], thyroid carcinoma [7], pancreatic carcinoma [8], esophageal cancer [9], gastric cancer [10] and colorectal cancers [11]. However, the relationship between abnormal expression of MMP1 and clinical outcome in BC patients remains unknown. Therefore, we investigated the expression of MMP1 in BC and its relationship with the clinicopathological features and clinical outcomes.

In this study, we conducted immunohistochemistry (IHC) assays to value the protein expression level of MMP1 in $\mathrm{BC}$ by using tissue microarray consisting of $107 \mathrm{BC}$ samples, and 36 paired IDBC and adjacent normal breast tissues. The relationships between MMP1 protein expression and clinicopathological features, such as age, nodal involvement, and ER, PR, HER2 status were also analyzed. We used Oncomine and breast cancer gene-expression miner (bc-GenExMiner) databases to assess MMP1 mRNA expression between $\mathrm{BC}$ cancer tissues and adjacent normal samples, and the correlations between MMP1 mRNA expression and clinicopathological characteristics. We then probed into the prognostic merit of MMP1 by survival analysis on the Kaplan-Meier Plotter database. Lastly, the genetic alterations and outcomes of cancer patients on cBioPortal online database were assessed.

\section{RESULTS}

\section{Protein level expression of MMP1 in breast cancer patients}

To investigate the protein expression level of MMP1 in BC, we assessed BC tissue samples and matched adjacent normal tissues from 36 human cases by using immunohistochemistry (IHC). IHC analysis indicated that MMP1 expression was significantly elevated in cancerous tissues compared with corresponding normal tissues $(\mathrm{p}=$ 0.003 ) (Figure 1A-1B).

\section{Relationship of MMP1 protein expression with the clinicopathological characteristics}

To better understand the relevance of MMP1 to BC, we divided the $143 \mathrm{BC}$ samples into groups based on the clinicopathological variables and evaluated the differences in MMP1 expression among these groups (Table 1). According to the classification of MMP1 IHC staining (Figure 1C), Positive MMP1 expression was observed to be positively related with the $\mathrm{T}$ stage $(\mathrm{p}=0.001)$, while the expression of MMP1 was negatively associated with ER and PR status $(\mathrm{p}=0.005$ and 0.027 , respectively). However, there were no significant association between MMP1 expression and other clinicopathologic factors including age, tumor location, differential grade, lymph node infiltration, and HER2 and triple-negative breast cancer (TNBC) status ( $\mathrm{p}=0.377,0.856,0.394,0.5,0.861$ and 0.188 , respectively).

\section{Transcription levels of MMP1 in breast cancer patients}

The mRNA expression feature of MMP1 was presented by using the SAGE Digital Gene Expression Display. Higher level of MMP1 mRNA in breast cancer tissue was identified compared with matched normal tissues (Supplementary Figure 1). Based on the Oncomine database, we discovered that MMP1 expression was significantly elevated in breast cancer samples compared with normal samples in nine datasets (Figure 2A). In TCGA's dataset, the transcription levels of MMP1 in different types of breast cancer were higher than normal tissues, including invasive ductal breast carcinoma (IDBC) with fold change $=11.254$, invasive lobular breast carcinoma (ILBC) with fold change $=3.972$, mixed lobular and ductal breast carcinoma (MLDBC) with fold change $=$ 3.278 , and male breast carcinoma (MBC) with fold change $=9.752$. (Figure 2B-2D).

\section{The relationship between mRNA levels of MMP1 and clinicopathological parameters of breast cancer patients}

In bc-GenExMiner, the Welch's test was performed to compare the mRNA expression of MMP1 among groups of patients in light of different clinicopathological parameters (Table 2). For age criterion, no significant differences between $\leq 51$ y and $>51$ y groups were found. BC patients with positive nodal status showed higher MMP1 expression than negative-nodal patients. ER and PR status were found to be negatively correlated with MMP1 expression. In BC patients with HER2 overexpression, the transcription level of MMP1 was significantly increased compared with HER2-negative groups. TNBC is a special type of BC, with ER (-), PR (-) and HER2 (-). We identified the expression level of MMP1 was significantly upregulated in non-TNBC patients. In Scarff Bloom \& Richardson grade status (SBR) criterion, more advanced SBR grade was associated with the higher mRNA level of MMP1 (Figure 3A). 


\section{The prognostic merit of MMP1 in breast cancer}

The prognostic merit of MMP1 mRNA expression was analyzed by using the online Kaplan-Meier Plotter database. The Kaplan-Meier curve and log-rank test analyses showed that increased levels of MMP1 were significantly correlated with worse overall survival (OS) (HR $=1.6$; 95\% CI: 1.29 $1.99, \mathrm{p}=1.6 \mathrm{e}-05)$, relapse free survival (RFS) $(\mathrm{HR}=1.78$; $95 \%$ CI: $1.59-1.98, \mathrm{p}<1 \mathrm{E}-16)$ and distant metastasis free survival $(\mathrm{DMFS})(\mathrm{HR}=1.65 ; 95 \% \mathrm{CI}: 1.35-2, \mathrm{p}=5.3 \mathrm{e}-05)$ for $\mathrm{BC}$ patients (Figure 3B-3D).

The relationship of MMP1 mRNA expression with lymph node status of BC patients was then investigated (Table 3). Upregulated MMP1 was significantly related to worse OS in negative-nodal patients ( $\mathrm{HR}=2.00,95 \% \mathrm{CI}: 1.36-2.92, \mathrm{p}=$ 0.00028 ), while not correlated to OS in positive-nodal patients $(\mathrm{HR}=1.13 ; 95 \%$ CI: $0.76-1.66, \mathrm{p}=0.55)$.

We then examined the correlation of MMP1 mRNA expression and clinical outcome in $\mathrm{BC}$ patients

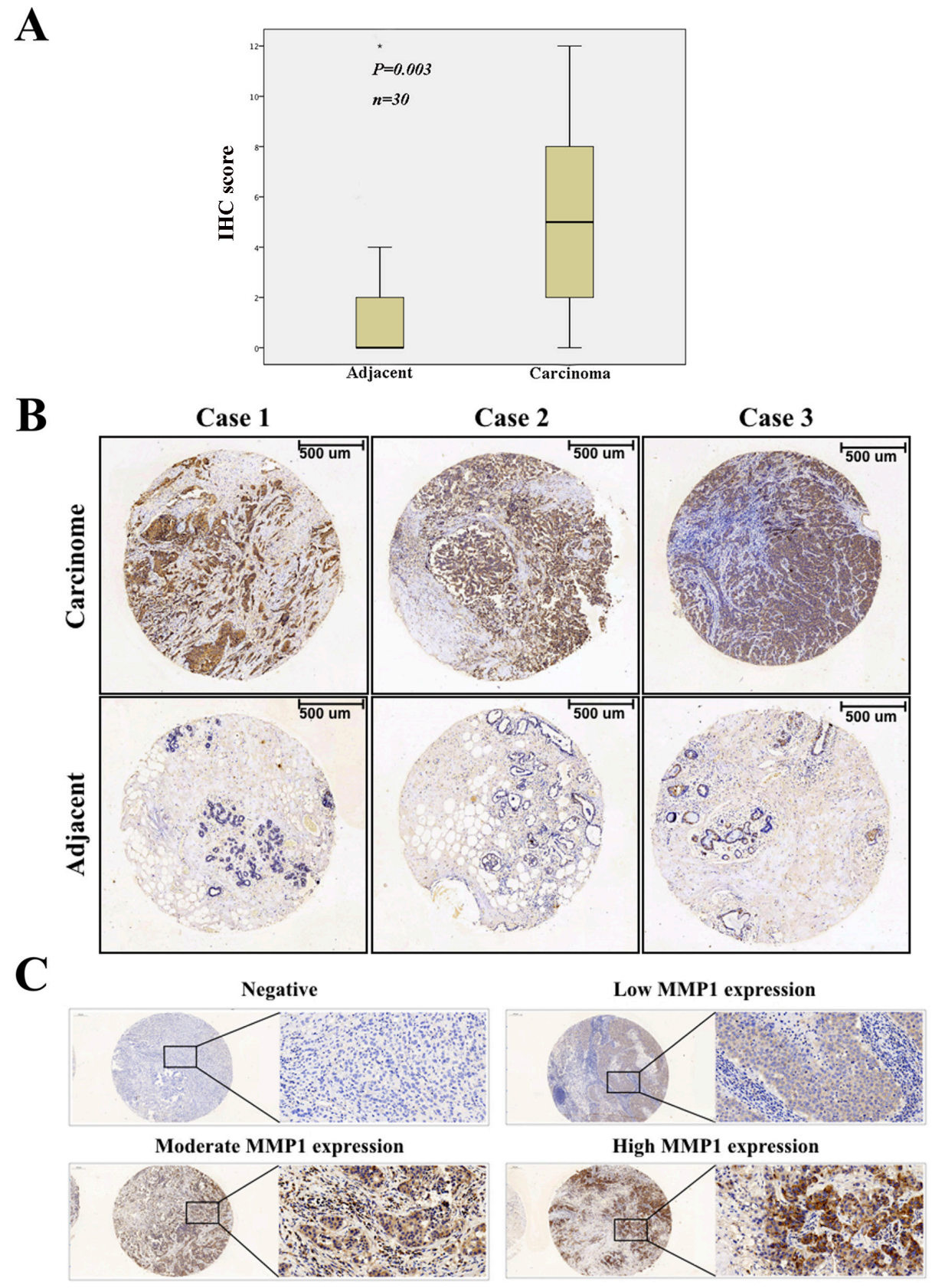

Figure 1: Immunohistochemical staining of MMP1 protein in BC. (A) Expression level of MMP1 in BC was significantly higher than corresponding controls $(\mathrm{p}=0.003)$. (B) Representative images of immunohistochemical staining of MMP1 expression in $\mathrm{BC}$ samples and matched adjacent normal tissues. (C) Negative, low, moderate and high MMP1 expression staining of BC. Scale bars, $100 \mu \mathrm{m}$. 
Table 1: Clinicopathological variables and the protein level expression of MMP1 in total BC patients according to the immunohistochemistry analysis

\begin{tabular}{|c|c|c|c|c|}
\hline \multirow[t]{2}{*}{ Characteristic } & \multirow[t]{2}{*}{ Cases } & \multicolumn{2}{|c|}{ MMP1 expression level } & \multirow[b]{2}{*}{$P$ value } \\
\hline & & $\begin{array}{l}\text { No. of Low } \\
\text { expression }\end{array}$ & $\begin{array}{l}\text { No. of High } \\
\text { expression }\end{array}$ & \\
\hline Age (years) & & & & 0.377 \\
\hline$<50$ & 52 & 24 & 28 & \\
\hline$>50$ & 90 & 34 & 56 & \\
\hline Tumor location & & & & 0.856 \\
\hline left & 74 & 26 & 48 & \\
\hline right & 58 & 22 & 36 & \\
\hline Differential grade & & & & 0.394 \\
\hline I & 4 & 1 & 3 & \\
\hline II & 96 & 43 & 53 & \\
\hline III & 36 & 12 & 24 & \\
\hline Lymph node infiltrated & & & & 0.5 \\
\hline Yes & 69 & 27 & 42 & \\
\hline No & 73 & 33 & 40 & \\
\hline $\mathrm{T}$ factor & & & & $0.001^{*}$ \\
\hline $\mathrm{T} 1 / 2$ & 112 & 55 & 57 & \\
\hline $\mathrm{T} 3 / 4$ & 27 & 4 & 23 & \\
\hline ER status & & & & $0.005^{*}$ \\
\hline Positive & 87 & 44 & 43 & \\
\hline Negative & 54 & 14 & 40 & \\
\hline PR status & & & & $0.027^{*}$ \\
\hline Positive & 70 & 36 & 34 & \\
\hline Negative & 72 & 23 & 49 & \\
\hline HER-2 status & & & & 0.861 \\
\hline Positive & 87 & 36 & 51 & \\
\hline Negative & 53 & 21 & 32 & \\
\hline TNBC status & & & & 0.188 \\
\hline TNBC & 17 & 4 & 13 & \\
\hline Non-TNBC & 124 & 53 & 71 & \\
\hline
\end{tabular}

with diverse ER, PR, and HER2 status (Table 3). MMP1 overexpression was associated with worse OS in ERpositive $\mathrm{BC}$ patients $(\mathrm{HR}=1.61 ; 95 \% \mathrm{CI}: 1.24-2.09, \mathrm{p}$ $=0.00027)$, but not associated with OS of ER-negative patients $(\mathrm{HR}=1.1 ; 95 \% \mathrm{CI}: 0.75-1.63, \mathrm{p}=0.62)$ MMP1 mRNA expression was found not linked to OS in both PRpositive and PR-negative $\mathrm{BC}$ patients $(\mathrm{HR}=1.34 ; 95 \%$ CI: 0.35-5.09, $\mathrm{p}=0.67 ; \mathrm{HR}=1.01 ; 95 \% \mathrm{CI}: 0.4-2.55$, $\mathrm{p}=0.98)$. High MMP1 mRNA expression was correlated to worse OS in HER2-negative $\mathrm{BC}$ patients $(\mathrm{HR}=3.17$; 95\% CI: $1.06-9.48, \mathrm{p}=0.029)$, but not related with OS of HER2-positive patients $(\mathrm{HR}=1.25 ; 95 \% \mathrm{CI}: 0.62-2.5$, $\mathrm{p}=0.53$ ).

To further probe into the correlation of MMP1 mRNA expression and survival, BC patients with diverse differentiation grades and molecular subtypes were also investigated. High MMP1 mRNA expression in grade II differentiated was associated with poor OS of BC patients 
Table 2: The relationship between mRNA expression of MMP1 and clinicopathological parameters of breast cancer (from the breast cancer gene-expression miner v4.0).

\begin{tabular}{|c|c|c|c|}
\hline Subgroup analysis & Cases & mRNA & p value \\
\hline \multicolumn{4}{|l|}{ Age } \\
\hline$\leq 51$ & 1392 & - & 0.2293 \\
\hline$>51$ & 2210 & - & \\
\hline \multicolumn{4}{|l|}{ Nodal status } \\
\hline negative & 2493 & - & $0.0040^{*}$ \\
\hline positive & 1562 & $\uparrow$ & \\
\hline \multicolumn{4}{|l|}{ ER (IHC) } \\
\hline negative & 1446 & $\uparrow$ & $<0.0001^{*}$ \\
\hline positive & 3766 & - & \\
\hline \multicolumn{4}{|l|}{ PR (IHC) } \\
\hline negative & 804 & $\uparrow$ & $<0.0001^{*}$ \\
\hline positive & 1249 & - & \\
\hline \multicolumn{4}{|l|}{ HER2 (IHC) } \\
\hline negative & 1409 & - & $=0.0001^{*}$ \\
\hline positive & 201 & $\uparrow$ & \\
\hline \multicolumn{4}{|l|}{ Triple-negative Status } \\
\hline Not & 374 & $\uparrow$ & $<0.0001^{*}$ \\
\hline TNBC & 3857 & - & \\
\hline
\end{tabular}

A

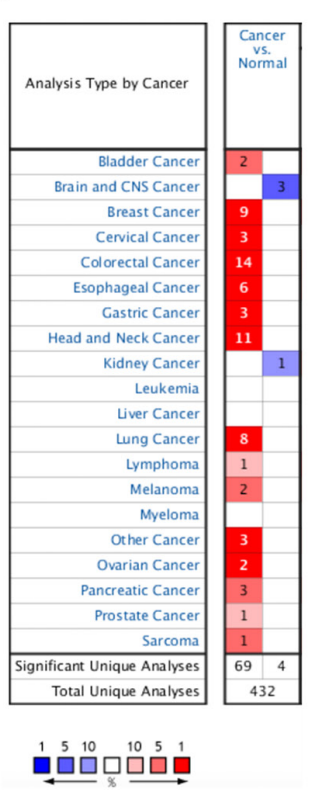

B

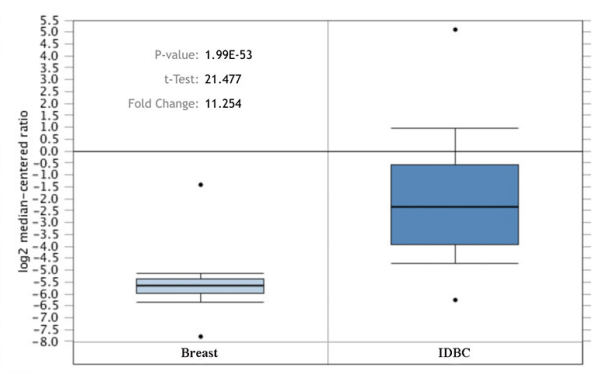

D

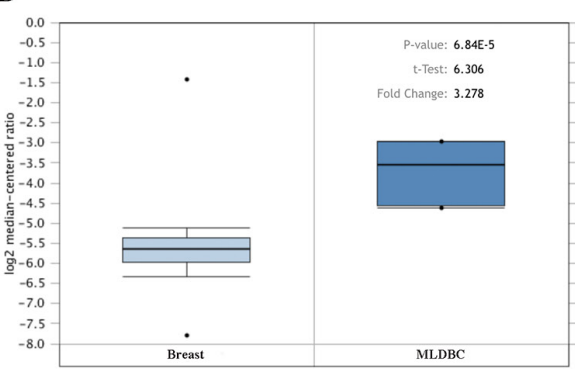

C

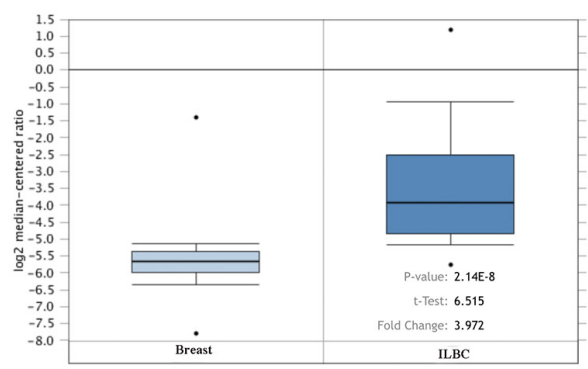

E

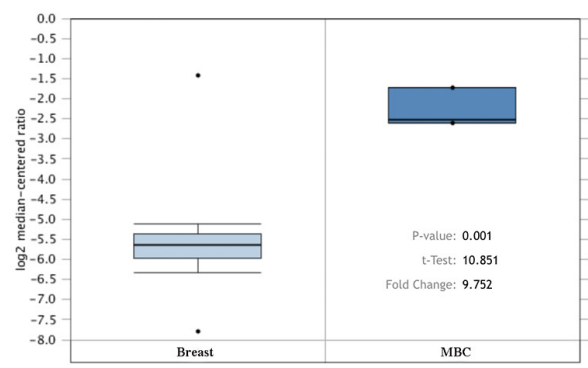

Figure 2: MMP1 mRNA expression in malignant tumors (Oncomine database). (A) The graph is a representation of the datasets with statistically significant mRNA overexpression (red) or reduced expression (blue) of MMP1 gene (cancer vs normal). Cell color was determined by the best gene rank percentile for the analyses within the cell, and the gene rank was analyzed by percentile of target gene in the top of all genes measured in each research. (B) Comparison of MMP1 mRNA expression between normal breast tissue and IDBC. (C) Comparison between normal breast tissue and ILBC. (D) Comparison between normal breast tissue and MLDBC. (E) Comparison between normal breast tissue and MBC. 
$(\mathrm{HR}=1.75 ; 95 \% \mathrm{CI}: 1.13-2.7, \mathrm{p}=0.011)$. But, grade I and III differentiated BC patients showed no correlation with OS of MMP1 mRNA expression ( $\mathrm{HR}=1.94$; 95\% CI: 0.764.94, $\mathrm{p}=0.16$; $\mathrm{HR}=1.1 ; 95 \% \mathrm{CI}: 0.8-1.53, \mathrm{p}=0.56)$. As for the molecular breast cancer subtype, upregulated MMP1 was significantly related to worse OS in luminal $\mathrm{A}$ and TNBC subtype patients (HR $=1.72 ; 95 \% \mathrm{CI}, 1.2-2.47$, p $=0.0028 ; \mathrm{HR}=1.65 ; 95 \% \mathrm{CI}: 1-2.71, \mathrm{p}=0.048)$, while not correlated to OS in luminal B and HER2-positive subtypes of $\mathrm{BC}$ patients $(\mathrm{HR}=1.3 ; 95 \% \mathrm{CI}$ : 0.9-1.89, $\mathrm{p}=0.16$; $\mathrm{HR}=$ 0.57; 95\% CI: 0.29-1.11, $\mathrm{p}=0.094$ ) (Figure 4A-4D).

\section{The impact of alterations in MMP1 on the clinical survival}

By using COSMIC, the pie chart described the mutations information including substitution nonsense, missense, synonymous, deletion frame and insertion frame shift. Substitution missense rate was $75.00 \%$ and deletion frameshift rate was $25.00 \%$ of mutant samples of BC. BC had $66.67 \% \mathrm{C}>\mathrm{G}$ and $33.33 \% \mathrm{G}>\mathrm{T}$ mutation in MMP1 coding strand (Figure 5A). Alteration frequency of MMP1 mutation in $\mathrm{BC}$ was analyzed by using cBioPortal. Less than $2 \%$ mutation in the patients with $\mathrm{BC}$ was observed (Figure 5B). After analyzed by Kaplan-Meier plot and logrank test, the alterations in MMP1 were correlated with worse OS $(p=0.00272)$ and DFS $(p=0.044)$ in BC patients with/ without MMP1 alterations (Figure 5C-5D).

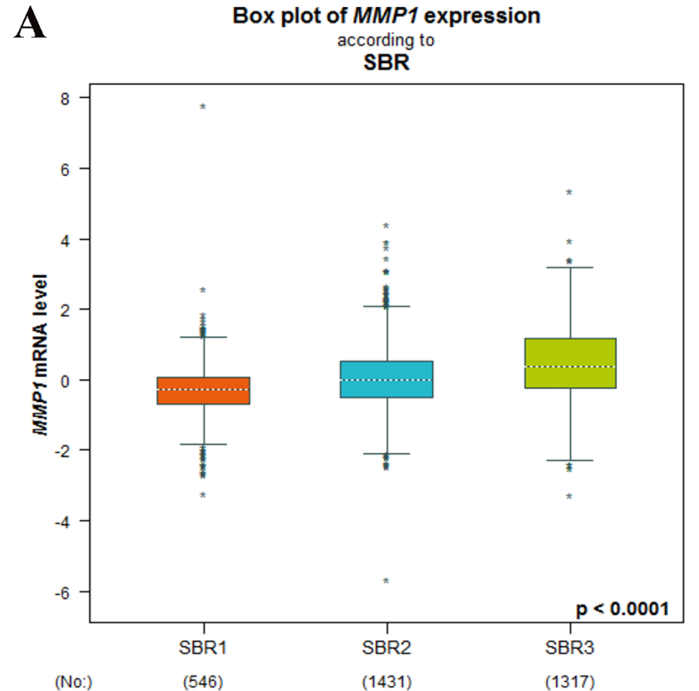

C

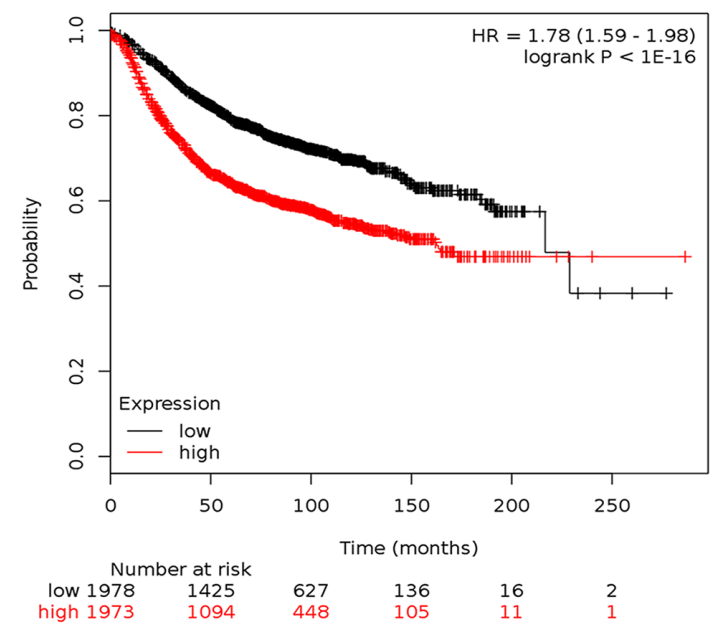

B

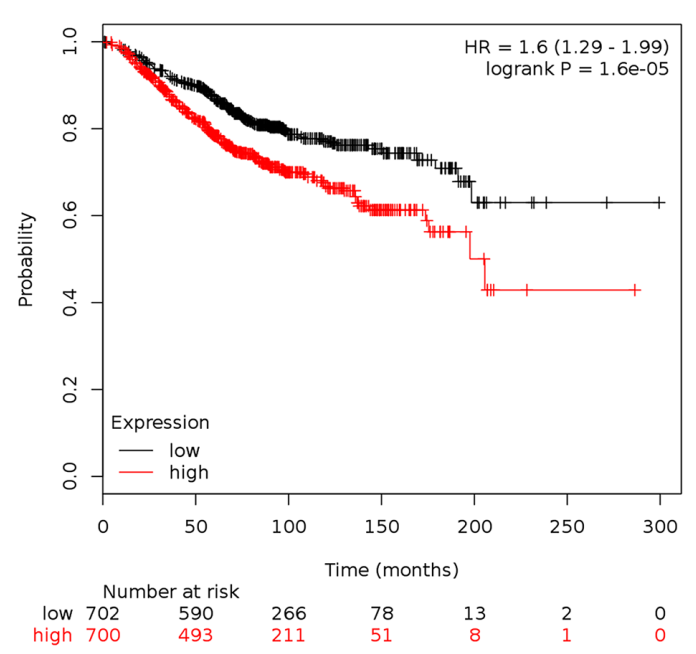

D

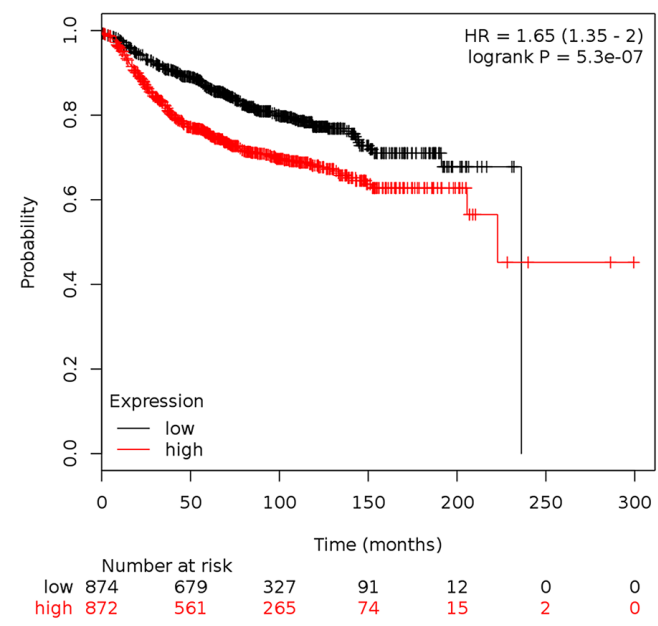

Figure 3: (A) The relationship between mRNA expression of MMP1 and SBR. The prognostic value of mRNA level of MMP1 in BC patients for (B) OS, (C) FP, and (D) DMFS in Kaplan-Meier plotter. 
Table 3: Correlation of MMP1 mRNA expression and clinical survival of breast cancer patients with different clinicopathological factors (from the Kaplan-Meier Plotter)

\begin{tabular}{lccc}
\hline Subgroup analysis & Patient number & HR $(\mathbf{9 5} \% \mathbf{C I})$ & P value \\
\hline Nodal status & & & $0.00028^{*}$ \\
negative & 594 & $2(1.36-2.92)$ & 0.55 \\
positive & 313 & $1.13(0.76-1.66)$ & 0.16 \\
Grade & & & $0.011^{*}$ \\
I & 161 & $1.94(0.76-4.94)$ & 0.56 \\
II & 387 & $1.75(1.13-2.7)$ & 0.62 \\
III & 503 & $1.1(0.8-1.53)$ & $0.00027^{*}$ \\
ER & & & \\
negative & 358 & $1.1(0.75-1.63)$ & 0.98 \\
positive & 1044 & $1.61(1.24-2.09)$ & 0.67 \\
PR & & & $0.029^{*}$ \\
negative & 89 & $1.01(0.4-2.55)$ & 0.53 \\
positive & 83 & $1.34(0.35-5.09)$ & \\
HER2 & & $3.17(1.06-9.48)$ & \\
negative & 130 & $1.25(0.62-2.5)$ & \\
positive & 129 & & \\
\hline
\end{tabular}

HR: hazard ratio; CI: confidence interval.
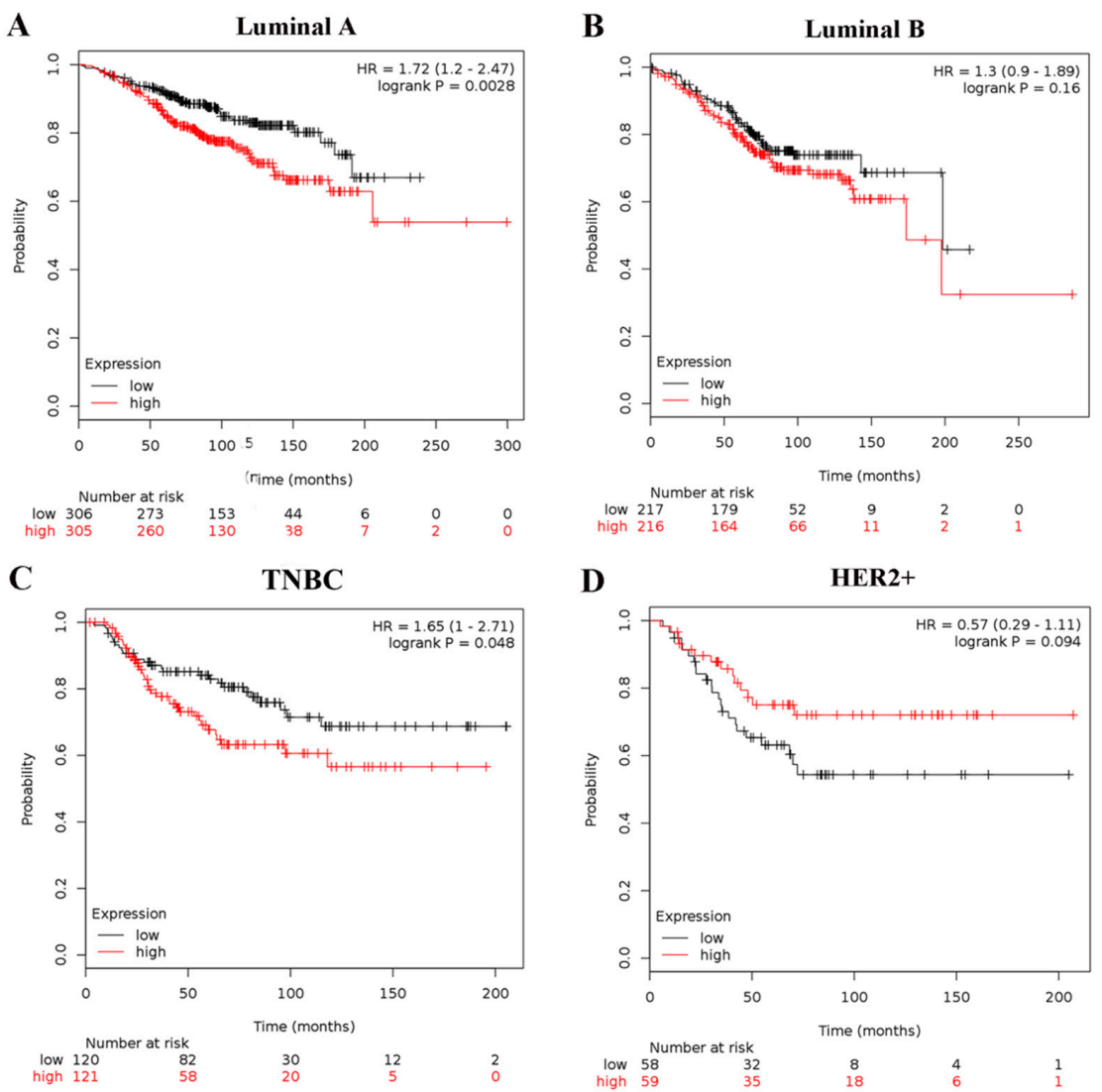

Figure 4: Association of MMP1 with different molecular subtypes of BC patients. OS curves are plotted for patients of (A) luminal A, (B) luminal B; (C) TNBC subtype; (D) HER2-positive. 


\section{DISCUSSION}

$\mathrm{BC}$ is one of the most common malignant tumors among women worldwide [1]. Although remarkable improvements in early detection and personalized therapeutics have decreased mortality of $\mathrm{BC}$ in recent years, the prevention and treatment of $\mathrm{BC}$ are still considerable public health concerns [12]. Therefore, novel prognostic indicators are necessary to further improve the prognosis of $\mathrm{BC}$ patients.

MMP1 is a proteolytic enzyme which degrades ECM, and its upregulated expression status has been detected among several kinds of malignant tumors $[6,13,14]$.
Animal researches revealed that overexpression status of MMP1 played a part in initiating mammary tumorigenesis through breaking down stroma and disseminating growth factors and mitogens for epithelial cells [15]. ECM degradation caused by MMP1 was proved to perturb the interactions between cell-cell and cell-ECM and separate cells from ECM, resulting in decreased apoptosis, enhanced cell division, and tumorigenesis [16]. Abnormal expression of MMP1 was identified in several types of malignant cancers [11, 17], but its expression status and prognostic merit in BC still remains unclear. Given the important role of MMP1 both in mechanism of cancer carcinogenesis and

A
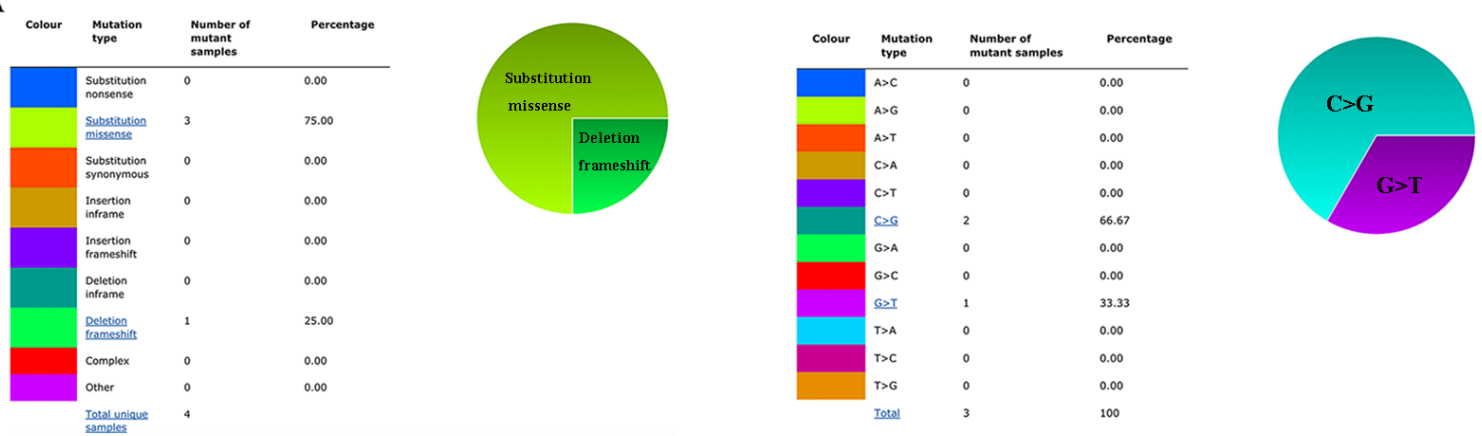

B
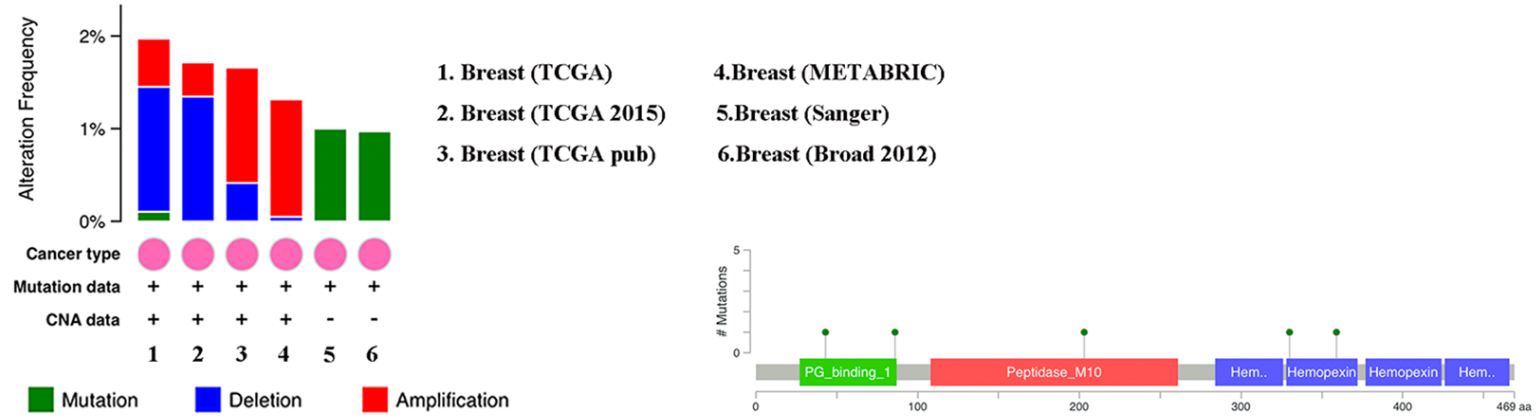

C

D
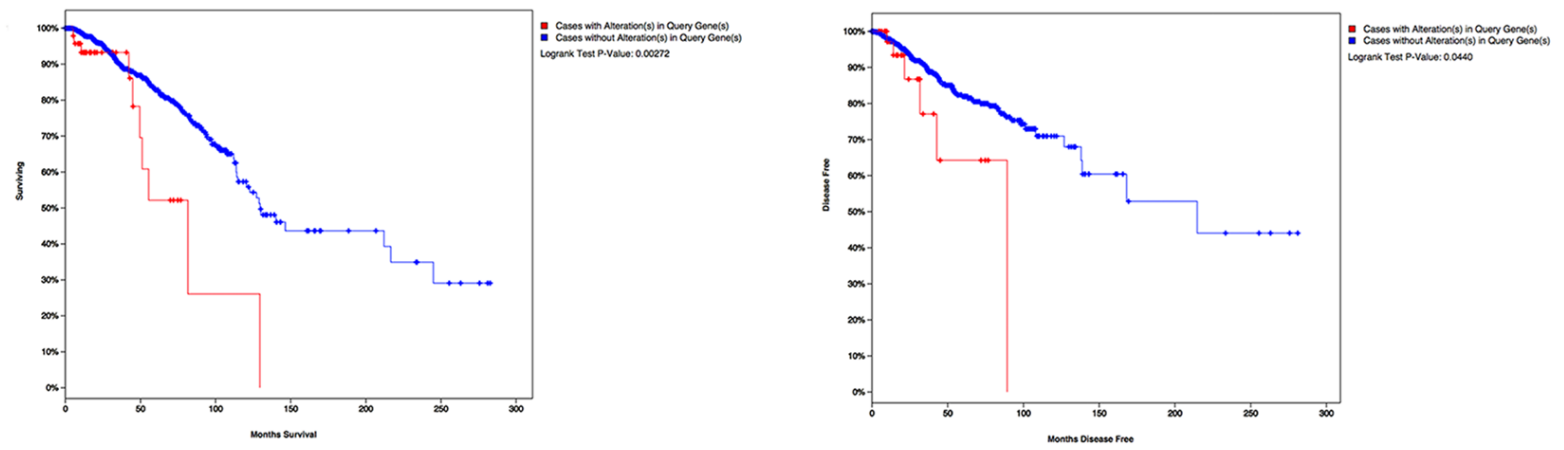

Figure 5: MMP1 genes expression and mutation analysis in breast invasive carcinoma (COSMIC and cBioPortal). (A) Pie-chart showed the percentage of the mutation type of MMP1 in BC according to COSMIC database. (B) Oncoprint in cBioPortal represented the proportion and distribution of samples with alterations in MMP1 gene. (C) Kaplan-Meier plots comparing OS in cases with/without MMP1 gene alterations. (D) Kaplan-Meier plots comparing disease free survival (DFS) in cases with/without MMP1 gene alterations. 
clinical application, we carried out this research to assess the clinical and prognostic importance of MMP1 in BC.

In IHC analysis, we identified that MMP1 protein expression was significantly upregulated in $\mathrm{BC}$ cancerous tissues than corresponding normal tissues. We also analyzed the relationship between MMP1 protein expression, tumor size, lymph node metastasis, differential grade, and ER, PR, HER2 status. We detected that MMP1 overexpression in $\mathrm{BC}$ significantly correlated with tumor size $(p=0.001), E R(p=0.005)$ and $P R(p=0.027)$ status. We then used Oncomine database to elucidate MMP1 mRNA expression in different types of cancers and different subtypes of BC. The results indicated that the MMP1 expression was significantly higher in tumor samples compared with normal samples at mRNA level. Thus, overexpression status of MMP1 in BC cancerous tissues compared with adjacent normal ones was verified at both mRNA and protein levels. And advanced SBR grade was positively correlated with higher mRNA level of MMP1.

Then, KM plotter was conducted to evaluate the correlation of MMP1 mRNA to clinical outcome. We concluded that the mRNA expression of MMP1 was associated to unfavorable OS, PFS and DMFS for all BC patients, which revealed that MMP1 mRNA expression may serve as an indicator for prevention and prognosis of BC. Regarding to nodal involvement and differential grade of patients with $\mathrm{BC}$, high expression of MMP1 contributed to worse OS in grade II and nodal-negative BC patients, whereas not associated to OS of grade I and III, and nodal-positive patients. As for the BC patients with different receptor subtypes, overexpression of MMP1 mRNA level was correlated to worse OS in ER-positive and HER2-negative BC patients, while not associated with ER-negative, HER2-positive patients. This result was consistent with the analysis about luminal A subtype (ER-positive and HER2-negative). HER2 is a member of epidermal growth factor receptor family and was identified to be overexpressed in $30 \%$ breast cancers $[18,19]$. HER2 played vital roles in the development and progression of some aggressive types of $\mathrm{BC}$, and was found to be related with poor clinical outcomes $[19,20]$. Thus, more researches are warranted to find out whether MMP1 protein influences the HER2 status or they perform competitively or collectively toward the prognosis in the BC setting. In light of our analysis, high expression of MMP1 mRNA was correlated with worse OS among grade II, nodal-negative, ER-positive and HER2-negative patients with BC.

Genetic polymorphisms are very important for malignant tumors, and can also impose vital impact as independent prognostic markers on therapeutic strategies for cancer patients. However, the role of MMP1 polymorphism remains controversial. Although one study revealed that MMP1 polymorphisms was found not correlated with BC risk in the assessment among 3,016 $\mathrm{BC}$ cases and 3,007 controls [21], other studies indicated that MMP1 single nucleotide polymorphisms (SNPs) were related to BC clinical survival [22]. MMP1 2G SNP was significantly correlated with $\mathrm{BC}$ progression and could be used as a prognostic indicator $[23,24]$. Based on current literature, MMP1 polymorphisms are promising biomarkers, and further researches should be carried out to figure out the prognostic role of MMP1 polymorphisms in BC patients.

In summary, results of our research involve some important implications. First, high MMP1 expressions at both mRNA and protein levels were found in BC cancer tissues compared with corresponding normal samples. Second, overexpression of MMP1 mRNA was related with unfavorable OS among grade II, nodal-negative, ER-positive and HER2-negative patients with BC. Third, the elevated expression of MMP1 was related with unfavorable survival outcome in BC patients, suggesting that MMP1 could serve as a prognostic indicator. Lastly, although further researches are required, MMP1 genetic polymorphisms are promising biomarkers for prognosis of $\mathrm{BC}$ patients.

\section{MATERIALS AND METHODS}

\section{Patients and samples}

Tissue microarray was provided by Servicebio (Wuhan, China). There were 179 samples included in the microarray with 107 invasive ductal breast cancer (IDBC) tumor tissues and another 36 paired IDBC and adjacent nonmalignant breast tissues.

\section{Immunohistochemistry}

Breast cancer tissue microarray (TMA) was heated, deparaffinized and were treated with citrate antigen repair buffer ( $\mathrm{pH}$ 6.0) to antigen repair, with 3\% hydrogen peroxide to block endogenous peroxidase activity, with $3 \%$ BSA to serum blocking. Tissue microarray was incubated with MMP1 primary antibody (1:200; polyclonal antibody; HuaAn Bio-Technology) and coordinate secondary antibody. Staining was displayed with DAKO DBA solution. Harris hematoxylin was used to re-stain the nucleus and TMA was dehydrated by alcohol.

The stained TMA was scanned using the Pannoramic Midi and analyzed using the Pannoramic Viewer (3D Histech) and Quant center. The software automatically identified and set all dark brown on the tissue slice $=3$, brown yellow $=2$, light yellow $=1$, blue nucleus $=0$, and the extent of stained cells $(0-5 \%=0 ; 5-25 \%=1 ; 26-50 \%=2 ; 51-$ $75 \%=3$ and $76-100 \%=4)$. The final score was determined by multiplying the intensity score and the score for the extent of stained cells, generating a score that ranged from 0 to 12 . The staining results were categorized into negative (score $0 ;-)$, low (score $1-4 ;+$ ), moderate (score $5-8 ;++$ ), and high (score $9-12 ;+++$ ). The results were evaluated by two independent pathologists. 


\section{Oncomine database analysis}

The online cancer microarray database, Oncomine (www.oncomine.org) [25] was used to assess the transcription levels of MMP1 in breast cancer (BC) specimens compared with that in normal controls by Students' $t$-test. The threshold of $p$ value, fold change and gene rank were $0.01,2$ and top $10 \%$, respectively.

\section{Serial analysis of gene expression (SAGE)}

All available published SAGE data were utilized for analysis of MMP1 gene expression between cancerous and normal tissues. Digital MMP1 gene expression profiles were evaluated by using SAGE Genie tools (http://www. ncbi.nlm.nih.gov/SAGE/) [26].

\section{Breast cancer gene-expression miner $\mathrm{v} 4.0$}

Breast Cancer Gene-Expression Miner v4.0 (bcGenExMiner v4.0) consisted 36 annotated genomic datasets and three statistical mining functions [27, 28]. The expression module was added on 2016/03/30, comparing the expression of a target gene based on clinical criteria, such as age, hormonal receptors, nodal status, and so on. The prognostic module evaluated the prognostic merit of candidate genes in human $\mathrm{BC}$ and provided potential prognostic indicators for $\mathrm{BC}$. The correlation module computed the association between genes or identified clusters of correlated co-expressed genes located in the same chromosomal region.

\section{The Kaplan-Meier Plotter}

The prognostic merit of MMP1 mRNA expression was appraised by an online database, Kaplan-Meier Plotter (www.kmplot.com) [29], which included gene expression data and survival information of clinical $\mathrm{BC}$ patients from Gene Expression Omnibus database. To analyze the overall survival (OS), relapse free survival (RFS) and distant metastasis free survival (DMFS) of patients with $\mathrm{BC}$, patient samples were split into two groups by median expression (high vs. low expression) and assessed by a Kaplan-Meier survival plot, with the hazard ratio (HR) with $95 \%$ confidence intervals $(\mathrm{CI})$ and log-rank $\mathrm{p}$ value. The Affymetrix ID is valid: 204475_s_at (MMP1).

\section{COSMIC analysis for mutations}

Catalogue of Somatic Mutations in Cancer (COSMIC) database (http://www.sanger.ac.uk/cosmic/) was utilized for assessment of MMP1 mutations [30]. Pie charts were generated for a distribution overview and substitutions on the coding strand in $\mathrm{BC}$.

\section{TCGA data and cBioPortal}

The Cancer Genome Atlas had both sequencing and pathological data on 30 different cancers [31]. The database query was based on mutation and altered expression of the MMP1 in invasive breast carcinoma (TCGA, Cell 2015; TCGA, Nature 2012; TCGA, Provisional; METABRIC, Nature 2012\& Nat Commun 2016; Sanger, Nature 2012; Broad 2012). The breast invasive carcinoma (TCGA, Provisional) dataset including data from 1105 samples with pathology reports was selected for further analyses of MMP1 using cBioPortal (www.cbioportal.org) [32, 33]. The genomic profiles included mutations, copy-number variance (CNV) from GISTIC, mRNA expression z-scores (RNA Seq V2 RSEM) and protein expression z-scores (RPPA). OS and DFS were calculated according to the cBioPortal's online instruction.

\section{Statistical analysis}

Statistical analysis was performed using SPSS 23.0 software. The expression of MMP1 in BC samples and corresponding adjacent tissues, as well as differential grade were compared by using the Wilcoxon test. Associations between MMP1 expression in BC tissues and clinicopathological features were assessed by chi-square test. All statistical tests were two-sided, and statistical significance was defined as $\mathrm{P}$ value less than 0.05 .

\section{ACKNOWLEDGMENTS AND FUNDING}

We thank all the group members for helpful discussions. The work is supported by National Natural Science Foundation of China (No. 81602471 and No. 81672729), by grant from Sub project of China National Program on Key Basic Research Project (973 Program) (No. 2014CB744505), and by grant from the Foundation of Education Department of Zhejiang Province (Y201636729).

\section{CONFLICTS OF INTEREST}

The authors declare that they have no competing interests.

\section{REFERENCES}

1. Siegel RL, Miller KD, Jemal A. Cancer Statistics, 2017. CA Cancer J Clin. 2017; 67:7-30.

2. Aznavoorian S, Murphy AN, Stetler-Stevenson WG, Liotta LA. Molecular aspects of tumor cell invasion and metastasis. Cancer. 1993; 71:1368-1383.

3. Liotta LA, Steeg PS, Stetler-Stevenson WG. Cancer metastasis and angiogenesis: an imbalance of positive and negative regulation. Cell. 1991; 64:327-336. 
4. Boire A, Covic L, Agarwal A, Jacques S, Sherifi S, Kuliopulos A. PAR1 is a matrix metalloprotease-1 receptor that promotes invasion and tumorigenesis of breast cancer cells. Cell. 2005; 120:303-313.

5. Altadill A, Rodriguez M, Gonzalez LO, Junquera S, Corte MD, Gonzalez-Dieguez ML, Linares A, Barbon E, Fresno-Forcelledo M, Rodrigo L, Vizoso FJ. Liver expression of matrix metalloproteases and their inhibitors in hepatocellular carcinoma. Digestive and liver disease. 2009; 41:740-748.

6. Du X, Wang S, Lu J, Cao Y, Song N, Yang T, Dong R, Zang L, Yang Y, Wu T, Li J. Correlation between MMP1-PAR1 axis and clinical outcome of primary gallbladder carcinoma. Japanese journal of clinical oncology. 2011; 41:1086-1093.

7. Mizrachi A, Koren R, Hadar T, Yaniv E, Morgenstern $\mathrm{S}$, Shvero J. Expression of MMP-1 in invasive welldifferentiated thyroid carcinoma. European archives of otorhino-laryngology. 2011; 268:131-135.

8. Ozden F, Saygin C, Uzunaslan D, Onal B, Durak H, Aki H. Expression of MMP-1, MMP-9 and TIMP-2 in prostate carcinoma and their influence on prognosis and survival. Journal of cancer research and clinical oncology. 2013; 139:1373-1382.

9. Murray GI, Duncan ME, O’Neil P, McKay JA, Melvin WT, Fothergill JE. Matrix metalloproteinase-1 is associated with poor prognosis in oesophageal cancer. The Journal of pathology. 1998; 185:256-261.

10. Inoue T, Yashiro M, Nishimura S, Maeda K, Sawada T, Ogawa Y, Sowa M, Chung KH. Matrix metalloproteinase-1 expression is a prognostic factor for patients with advanced gastric cancer. International journal of molecular medicine. 1999; 4:73-77.

11. Murray GI, Duncan ME, O’Neil P, Melvin WT, Fothergill JE. Matrix metalloproteinase-1 is associated with poor prognosis in colorectal cancer. Nature medicine. 1996; 2:461-462.

12. Carlson RW, Allred DC, Anderson BO, Burstein HJ, Edge SB, Farrar WB, Forero A, Giordano SH, Goldstein LJ, Gradishar WJ, Hayes DF, Hudis CA, Isakoff SJ, et al. Metastatic breast cancer, version 1.2012: featured updates to the NCCN guidelines. Journal of the National Comprehensive Cancer Network. 2012; 10:821-829.

13. Grimm M, Lazariotou M, Kircher S, Stuermer L, Reiber C, Hofelmayr A, Gattenlohner S, Otto C, Germer CT, von Rahden BH. MMP-1 is a (pre-)invasive factor in Barrettassociated esophageal adenocarcinomas and is associated with positive lymph node status. J Transl Med. 2010; 8:99.

14. Ito T, Ito M, Shiozawa J, Naito S, Kanematsu T, Sekine I. Expression of the MMP-1 in human pancreatic carcinoma: relationship with prognostic factor. Mod Pathol. 1999; 12:669-674.

15. Otani Y, Okazaki I, Arai M, Kameyama K, Wada N, Maruyama K, Yoshino K, Kitajima M, Hosoda Y, Tsuchiya $\mathrm{M}$. Gene expression of interstitial collagenase (matrix metalloproteinase 1) in gastrointestinal tract cancers. J Gastroenterol. 1994; 29:391-397.

16. Duffy MJ, Maguire TM, Hill A, McDermott E, O'Higgins N. Metalloproteinases: role in breast carcinogenesis, invasion and metastasis. Breast cancer research. 2000; 2:252-257

17. Sunami E, Tsuno N, Osada T, Saito S, Kitayama J, Tomozawa S, Tsuruo T, Shibata Y, Muto T, Nagawa H. MMP-1 is a prognostic marker for hematogenous metastasis of colorectal cancer. Oncologist. 2000; 5:108-114.

18. Yarden Y. Biology of HER2 and its importance in breast cancer. Oncology. 2001; 61:1-13.

19. Slamon DJ, Clark GM, Wong SG, Levin WJ, Ullrich A, McGuire WL. Human breast cancer: correlation of relapse and survival with amplification of the HER-2/neu oncogene. Science (New York, NY). 1987; 235:177-182.

20. Holbro T, Beerli RR, Maurer F, Koziczak M, Barbas CF 3rd, Hynes NE. The ErbB2/ErbB3 heterodimer functions as an oncogenic unit: ErbB2 requires ErbB3 to drive breast tumor cell proliferation. Proceedings of the National Academy of Sciences of the United States of America. 2003; 100:8933-8938.

21. Beeghly-Fadiel A, Cai Q, Lu W, Long J, Gao YT, Shu XO, Zheng W. No association between matrix metalloproteinase-1 or matrix metalloproteinase-3 polymorphisms and breast cancer susceptibility: a report from the Shanghai Breast Cancer Study. Cancer epidemiology, biomarkers \& prevention. 2009; 18:1324-1327.

22. Slattery ML, John E, Torres-Mejia G, Stern M, Lundgreen A, Hines L, Giuliano A, Baumgartner K, Herrick J, Wolff RK. Matrix metalloproteinase genes are associated with breast cancer risk and survival: the Breast Cancer Health Disparities Study. PloS one. 2013; 8:e63165.

23. Tower GB, Coon CI, Brinckerhoff CE. The $2 \mathrm{G}$ single nucleotide polymorphism (SNP) in the MMP-1 promoter contributes to high levels of MMP-1 transcription in MCF-7/ADR breast cancer cells. Breast Cancer Res Treat. $2003 ; 82: 75-82$.

24. Zhou J, Brinckerhoff C, Lubert S, Yang K, Saini J, Hooke J, Mural R, Shriver C, Somiari S. Analysis of matrix metalloproteinase-1 gene polymorphisms and expression in benign and malignant breast tumors. Cancer investigation. 2011; 29:599-607.

25. Rhodes DR, Yu J, Shanker K, Deshpande N, Varambally R, Ghosh D, Barrette T, Pandey A, Chinnaiyan AM. ONCOMINE: a cancer microarray database and integrated data-mining platform. Neoplasia. 2004; 6:1-6.

26. Velculescu VE, Zhang L, Vogelstein B, Kinzler KW. Serial analysis of gene expression. Science (New York, NY). 1995; 270:484-487.

27. Jezequel P, Campone M, Gouraud W, Guerin-Charbonnel C, Leux C, Ricolleau G, Campion L. bc-GenExMiner: an easy-to-use online platform for gene prognostic analyses in breast cancer. Breast Cancer Res Treat. 2012; 131:765-775. 
28. Jezequel P, Frenel JS, Campion L, Guerin-Charbonnel C, Gouraud W, Ricolleau G, Campone M. bc-GenExMiner 3.0: new mining module computes breast cancer gene expression correlation analyses. Database (Oxford). 2013; 2013:bas060.

29. Gyorffy B, Surowiak P, Budczies J, Lanczky A. Online survival analysis software to assess the prognostic value of biomarkers using transcriptomic data in non-small-cell lung cancer. PLoS one. 2013; 8:e82241.

30. Forbes SA, Beare D, Gunasekaran P, Leung K, Bindal N, Boutselakis H, Ding M, Bamford S, Cole C, Ward S, Kok CY, Jia M, De T, et al. COSMIC: exploring the world's knowledge of somatic mutations in human cancer. Nucleic acids research. 2015; 43:D805-811.
31. Cancer Genome Atlas Network. Comprehensive molecular portraits of human breast tumours. Nature. 2012; 490:61-70.

32. Gao J, Aksoy BA, Dogrusoz U, Dresdner G, Gross B, Sumer SO, Sun Y, Jacobsen A, Sinha R, Larsson E, Cerami E, Sander C, Schultz N. Integrative analysis of complex cancer genomics and clinical profiles using the cBioPortal. Science signaling. 2013; 6:pl1.

33. Cerami E, Gao J, Dogrusoz U, Gross BE, Sumer SO, Aksoy BA, Jacobsen A, Byrne CJ, Heuer ML, Larsson E, Antipin Y, Reva B, Goldberg AP, et al. The cBio cancer genomics portal: an open platform for exploring multidimensional cancer genomics data. Cancer discovery. 2012; 2:401-404. 